\title{
Post Evaluation System of Bridge Preventive Maintenance Based on Gray Fuzzy Comprehensive Judgment
}

\author{
Wang Wei \\ Research Institute of Highway Ministry of Transport \\ No.8, Xitucheng Road, Haidian District, Beijing, China, 100088 \\ 20217161@qq.com
}

\begin{abstract}
This paper attempts to establish a post evaluation system framework for the implementation effect of bridge preventive maintenance based on the gray multi-level fuzzy comprehensive evaluation. It proposes to use analytic hierarchy process to determine the index weight and introduces the gray fuzzy comprehensive evaluation to determine the comprehensive evaluation value of bridge preventive maintenance. The case analysis shows that this method can more objectively evaluate the implementation effect of bridge preventive maintenance and it has good operability and practicability.
\end{abstract}

Keywords: Bridge preventive maintenance; post evaluation; gray fuzzy comprehensive evaluation; analytic hierarchy process; implementation effect.

\section{Introduction}

Bridges are the lifeline of smooth traffic and the throat of highways; new requirements are needed for bridge maintenance that it is necessary to guarantee the bridge operation safety and the expected service life, so as to achieve sustainable development of highway bridges and solve the problem of short service life. According to the decline law of material and structure under the action of environment, etc, it is necessary to intervene the bridge properly to ensure that the bridge reaches its design life or remaining life and the corresponding functions, with the most reasonable cost of life cycle.

Based on the research and analysis of the achievements of highway construction projects and preventive maintenance projects by way of post evaluation method and combined with the characteristics of preventive maintenance project, this paper sets up a post evaluation method suitable for the characteristics of the preventive maintenance technology of bridges, so as to perfect the theoretical system of post evaluation of highway construction in China.

\section{Establishment of comprehensive index system of post evaluation of bridge preventive maintenance}

According to the characteristics of the bridge preventive maintenance project and the research results mentioned above, the comprehensive evaluation index system of bridge preventive maintenance effect, including target evaluation, implementation process evaluation, technical evaluation, benefit evaluation, impact evaluation, continuous evaluation and other indicators) is determined, with the established comprehensive evaluation index system of post evaluation of bridge preventive maintenance effect shown in Fig.1.

\section{Grey multi-level fuzzy comprehensive post evaluation model of bridge preventive maintenance}

\section{The determination of success degree and the evaluation of the base index evaluation value}

According to the success degree comprehensive evaluation index system, the success degree base index expert questionnaire is made, with the remark set quantized into 5 grades for the success degree index (see Table1). 


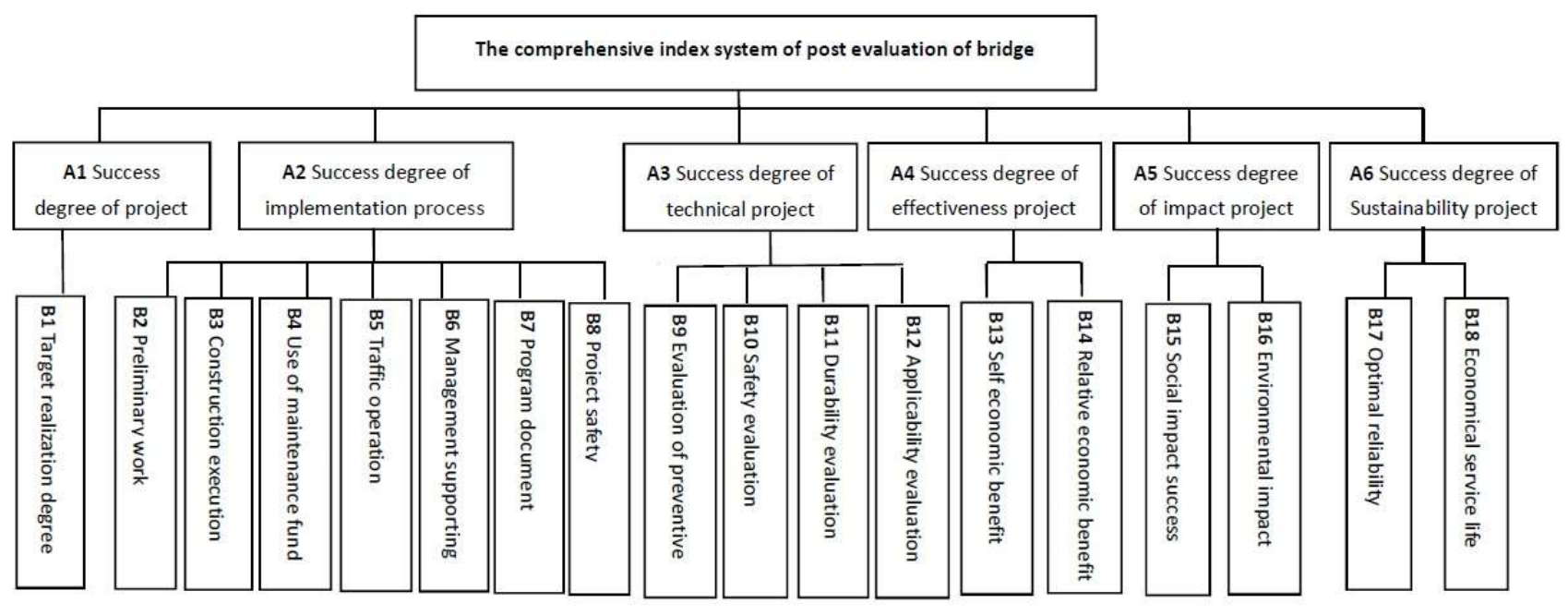

Fig. 1 The comprehensive index system of post evaluation of bridge preventive maintenance

Table 1 Standard score of evaluation index

\begin{tabular}{|c|c|c|c|c|c|}
\hline Grade & $\mathbf{5}$ & $\mathbf{4}$ & $\mathbf{3}$ & $\mathbf{2}$ & $\mathbf{1}$ \\
\hline Remark set & Complete success & Success & Partial success & Failure & Failure \\
\hline Index number & 9 & 7 & 5 & 3 & 1 \\
\hline
\end{tabular}

\section{The determination of index weights in the post evaluation system}

In the multi-level comprehensive evaluation system, the importance degree of each evaluation index is usually different, the weight should be determined in a reasonable and scientific way, or it will directly affects the accuracy of the evaluation, and the analytic hierarchy process is used to determine the weight. The latent root method is the one that is relatively mature and widely used in AHP. A consistency check is required for the single guideline ordering of each hierarchy. The consistency index $C I=\frac{\lambda_{\max }-n}{n-1}$ is introduced, wherein, $\lambda_{\max }$ is the maximum eigenvalue of matrix A, and $n$ is the dimension of the judgment matrix. Professor Saaty has provided the average random consistency index $R I$; according to the Table: when $n \geq 3, C R=\frac{C I}{R I}$ is served as the consistency ratio, when $C R<0.1$, it is deemed that the consistency of the judgment matrix is acceptable, or an appropriate change can be made for the judgment matrix.

Then the weight matrix of index at all levels can be obtained, the secondary index weight matrix:

$$
X_{i}=\left(w_{i 1}, w_{i 2, \ldots,}, w_{i n}\right) \quad(i=1,2, . .6)
$$

The primary index weight matrix:

$$
X=\left(w_{1}, w_{2}, w_{3}, w_{4}, w_{5}, w_{6}\right)
$$

\section{Evaluation sample matrix}

In the case of determining the evaluation index system and evaluating index weights, according to the evaluation index $u_{i j}$ grading standard (see Table 1), the evaluation index detection is scored by $l$ experts, and then $l$ evaluation values of the evaluation index is obtained. Then, the evaluation sample matrix is: $D_{i}$

$$
D_{i}=\left[\begin{array}{rrrr}
d_{i 1}^{(1)} & d_{i 1}^{(2)} & \Lambda & d_{i 1}^{(l)} \\
d_{i 2}^{(1)} & d_{i 2}^{(2)} & \Lambda & d_{i 2}^{(l)} \\
\mathrm{M} & \mathrm{M} & & \mathrm{M} \\
d_{i n}^{(1)} & d_{i n}^{(2)} & \Lambda & d_{i n}^{(l)}
\end{array}\right] \begin{gathered}
u_{i 2} \\
u_{i n}
\end{gathered}
$$




\section{Whitening weight function}

According to the grading standard, $e=1,2,3,4,5$ evaluation gray class is obtained and the corresponding whitening right function is $f_{1}(x), f_{2}(x), \Lambda, f_{5}(x)$ 。 Then, the whitening right function of each gray class is:

$$
\begin{aligned}
& f_{1}(x)= \begin{cases}\frac{1}{9} x & 0 \leq x<9 \\
1 & x \geq 9\end{cases} \\
& f_{2}(x)= \begin{cases}\frac{1}{7} x & 0 \leq x<7 \\
\frac{1}{2}(9-x) & 7 \leq x \leq 9\end{cases} \\
& f_{3}(x)= \begin{cases}\frac{1}{5} x & 0 \leq x<5 \\
\frac{1}{4}(9-x) & 5 \leq x \leq 9\end{cases} \\
& f_{4}(x)= \begin{cases}\frac{1}{3} x & 0 \leq x<3 \\
\frac{1}{6}(9-x) & 3 \leq x \leq 9\end{cases} \\
& f_{5}(x)= \begin{cases}0 & 0 \leq x<1 \\
\frac{1}{8}(9-x) & 1 \leq x \leq 9\end{cases}
\end{aligned}
$$

\section{Grey evaluation weight}

For the evaluation index, the evaluation object belongs to the gray evaluation coefficient of No. $e(e=1,2,3,4,5)$ evaluation gray class

$$
X_{i j e}=\sum_{e=1}^{5} f_{e}\left(d_{i j}^{(e)}\right)
$$

For the evaluation index $u_{i j}$, the evaluation object belongs to the total number of gray evaluation of each evaluation gray class:

$$
X_{i j}=\sum_{e=1}^{5} X_{i j e}
$$

The evaluation object belongs to the gray evaluation weight of No. $e(e=1,2,3,4,5)$ gray class

$$
r_{i j}^{(e)}=X_{i j e} / X_{i j}
$$

Therefore, gray evaluation weight vector $r_{i j}=\left(r_{i j}^{(1)}, r_{i j}^{(2)}, r_{i j}^{(3)}, r_{i j}^{(4)}, r_{i j}^{(5)}\right), u_{i j}$ belongs to index $u_{i}$, and gray evaluation weight matrix for each evaluation gray class:

$$
R_{i}=\left[\begin{array}{c}
r_{i 1} \\
r_{i 2} \\
\mathrm{M} \\
r_{i n}
\end{array}\right]=\left[\begin{array}{cccc}
r_{i 1}^{(1)} & r_{i 1}^{(2)} & \Lambda & r_{i 1}^{(5)} \\
r_{i 2}^{(1)} & r_{i 2}^{(2)} & \Lambda & r_{i 2}^{(5)} \\
\mathrm{M} & \mathrm{M} & & \mathrm{M} \\
r_{i n}^{(1)} & r_{i n}^{(2)} & \Lambda & r_{i n}^{(5)}
\end{array}\right]
$$

\section{Comprehensive evaluation value}

A comprehensive evaluation is made to index $u_{i}$ of the evaluation object, and the evaluation results

$$
B_{i}=A_{i} \cdot R_{i}=\left(b_{i 1}, b_{i 2}, b_{i 3}, b_{i 4}, b_{i 5}\right)
$$


Gray evaluation weight matrix for each evaluation gray class

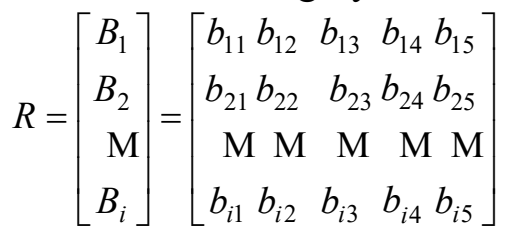

Therefore, a comprehensive evaluation is made to the evaluation object $u$, and the results are as follows:

$$
B=A \cdot R=\left(b_{1}, b_{2}, b_{3}, b_{4}, b_{5}\right)
$$

According to Table 1, vector $C=(9,7,5,3,1)^{T}$, of various evaluation rating grades is taken, and the final comprehensive evaluation value is:

$$
Z=B \cdot C
$$

\section{Conclusion}

Take Dongzhai New Bridge of some Province as an example, the comprehensive post-evaluation value $Z=5.05$ of implementation effect assessment of this project is in middle of partial success and total success, which shows that the bridge preventive maintenance implemented this time is effective but some targets are still need to be improved. Anticipated goals can be achieved through circulation feedback, adjustment and improvement.

The combination of analytic hierarchy process and gray multi-level fuzzy evaluation method in this paper makes post-evaluation of bridge preventive maintenance effect becomes more convenient and scientific, provides a practical and highly reliable method to post-evaluation of bridge preventive maintenance effect at the same time, and it also has very important, practical significance in the improvement of highway post-evaluation system in China.

\section{Reference}

[1] Profession Standard Of The People's Republic Of China. Code for Maintenance Highway Bridge and Culvert(JTG H11-2004)[S].Beijing: China Communication Press, 2004.

[2] Management Measures for Post Evaluation Work of Highway Construction Projects. Ministry of Transport of the People's Republic of China, 2011.

[3] Jiang Weixing,Zhang sanli. Post Evaluation of Investment Projects[M]. Beijing: China Petrochemical Press,2001.

[4] Wang Yingluo. System Engineering[M]. Beijing: China Machine Press, 2006.

[5] Deng Julong. Basis of Grey Theory[M] . Wuhan: Huazhong University of Science and Technology (HUST) Press,2002.

[6] Ye Yicheng Ke Lihua. System Comprehensive Evaluation Technology and Application[M]. Beijing: Metallurgical Industry Press,2006. 